board last week that he shared the enthusiasm for such a project, although arguing that it should be planned in conjunction with what is likely to be NASA's next major project, a permanent orbiting space station which could be used as a base for manned planetary missions.

Members of the advisory board wondered whether there might be a danger that if NASA did embark on such a project it might further squeeze the space science budget, as the Apollo Moon landings and the space shuttle appeared to have done, but Dr Beggs tried to calm such fears. Admitting that the near-term looked relatively bleak, with no new planetary starts likely to be approved for 1983 or 1984 , he replied that in the past the space science budget had done best precisely at those times when NASA had been able to generate political support for its major undertakings.

David Dickson
Diablo Canyon reactor

\section{Licence revoked}

\section{Washington}

The US nuclear industry has come in for an unexpected roasting from the new chairman of the Nuclear Regulatory Commission (NRC), Dr Nunzio Palladino. His criticism of its quality control was made before a congressional committee on the same day that the NRC voted to revoke a licence issued only two months ago to permit start-up tests at the Diablo Canyon nuclear reactor in California, on the basis of a series of engineering mistakes made when the plant was strengthened to resist earthquakes in the mid-1970s.

Six weeks of frequently-violent demonstrations by anti-nuclear protesters in September and October failed to stop the plant's owners, Pacific Gas and Electric

\section{More bickering about solar satellites}

\section{Washington}

The National Aeronautics and Space Administration (NASA) seems unlikely to grant the request from the European Space Agency (ESA) to bring forward the launch of the International Solar Polar Mission, now due in 1986.

ESA had made this request following NASA's decision to stop work on the vehicle which it was to have provided for a dual-spacecraft mission, with the original intention that the two would pass simultaneously in opposing orbits over the poles of the Sun. European scientists had hoped that NASA, which will still launch the ESA space vehicle from the space shuttle, would be able to arrange an earlier flight to help compensate for the disruption and the loss of experiments which the cancellation has caused.

Last week, however, NASA officials said that the growing concern over whether the shuttle will be able to maintain an already overcrowded launch schedule means that a 1984 launch is virtually out of the question.

There is a slight possibility of a launch in 1985. However, since there is only a relatively short launch window in that year, and since the same window is required by the Galileo probe and orbiter scheduled to start its journey to Jupiter at the same time, the chances of arranging both launches within the same period seem slim.

ESA officials are still angry at the way in which NASA cancelled its proposed spacecraft; a resolution adopted by ESA's space programme committee last month suggested that ways should be explored of seeking some type of compensation from the US agency and ESA's secretary general Dr Quistgaard suggested the early launch date as one form of recompense.

US officials admit that it is the first time NASA has had to go back on a previous agreement, but claim that the "memorandum of understanding" signed between the two organizations makes it clear that the solar mission agreement was subject to the availability of funding, and that NASA could not legally commit itself to more than one year's advance funding.

In addition, Dr Hans Mark, deputy administrator of NASA, told a recent meeting at the National Academy of Sciences that although the decision to cancel NASA's involvement in the solar mission was regrettable, there had been several occasions in the past when European governments had broken commitments, for example some of those made through the North Atlantic Treaty Organization.

On the first point, ESA claims that the memorandum of understanding had been agreed on the basis that normal funding procedures would be pursued by both sides - and that NASA is at fault not for having failed to provide the funding promised, but for having decided unilaterally to omit the project from its request to the Office of Management and Budget for the 1983 budget. On the point that some European organizations have broken commitments in the past, ESA argues that it is not fair to penalize ESA for failures of individual European states.

Meanwhile NASA scientists are discussing the possibility of launching an Explorer satellite into an ecliptic orbit around the Sun to coincide with the European spacecraft's encounter. This satellite, which would be launched in 1985, would provide baseline measurements of the solar wind - and that might go some way to making up for the deficiencies resulting from the decision not to send a full US spacecraft.
Company, from proceeding with plans to start to load the reactor with uranium. The protesters claim that the plant is inherently unsafe because it has been built less than three miles from the Hosgri Fault, a branch of the San Andreas Fault system.

As the demonstrations were coming to an end, however, an engineer with the company discovered that a blueprint had been misread when the plant's support structure was being strengthened to compensate for the possibility of earthquake damage, causing the loads on various components to be miscalculated. Further errors found later included the misapplication of stress level numbers along the Hosgri Fault and the use of incorrect data in calculating the ability of pipes to withstand an earthquake.

Besides causing considerable embarrassment to the Pacific Gas and Electric Company, this discovery led to immediate pressure on NRC from Congress. The Reagan Administration has promised to speed up the licensing of new plants; but this strategy requires that public confidence should be maintained that safety is not being sacrificed in the process.

Appearing before the House Interior subcommittee, Dr Palladino, former dean of engineering at Pennsylvania State University, said that "'after reviewing both industry and NRC past performance in quality assurance, I readily acknowledge that neither have been as effective as they should have been in view of the relatively large number of construction-related deficiencies that have come to light".

An order approved by the five-man commission, which voted 4-1 to suspend the low-power operating licence and unanimously for an independent audit of the quality control safeguards used by Pacific Gas and Electric Company, said that the suspension was necessitated by the seriousness of the errors in the initial review of safety modifications.

Following NRC's decision, the Pacific Gas and Electric Company issued a statement saying that it was "disappointed", since "nothing has been discovered to date that would indicate that the plant is not safe"'. The company claims that the plant had many redundant safety systems compensate for any threat from the Hosgri Fault.

David Dickson

\section{Uranium enrichment}

\section{US-India stand-off}

\section{New Delhi}

India is trying to become self-sufficient in the production of fuel for its nuclear power plants following its bitter experience with the United States over the supply of low enriched uranium for the Tarapur plant in Maharashtra state.

The latest round of discussions between Indian and US of ficials has failed to break the impasse over the clearance of at least pending applications with the United 